\title{
Anestesia local para ovariectomia em gatas
}

\section{Local anesthesia for ovariectomy in cats ${ }^{1}$}

\author{
Ana Maria Quessada²; Cleide Selma Alves Santana33; Helbert Lopes da Silva ${ }^{4}$
}

\begin{abstract}
Resumo: Com o objetivo de se propor uma técnica eficiente, barata e segura para se anestesiar gatas, foram realizadas ovariectomias em 15 animais. As gatas foram tranqüilizadas com acepromazina $0,2 \%$ na dose de $5 \mathrm{mg} / \mathrm{kg}$. As cirurgias foram realizadas através de laparotomia bilateral pelo flanco com anestesia local infiltrativa, utilizando-se lidocaína a $2 \%$ na dose máxima de $7 \mathrm{mg} / \mathrm{kg}$. Para localização dos ovários tomou-se como referência anatômica os rins, os quais foram identificados por palpação externa. Após abertura da cavidade abdominal, os ovários foram exteriorizados, pinçados e ligados por transfixação, procedendo-se à sua extirpação. A parede abdominal foi fechada em massa com pontos separados simples e a pele foi suturada da mesma maneira. Uma semana após a cirurgia foi feita a retirada dos pontos cutâneos. A anestesia mostrou-se eficiente para a cirurgia em questão e esta revelou-se de fácil execução. Por ocasião da retirada dos pontos, as gatas foram examinadas clinicamente e não mostraram reações patológicas dignas de nota. Concluiu-se que a técnica anestésica pode ser utilizada para ovariectomia pelo flanco em gatas com sucesso.
\end{abstract}

Palavras-chave: anestesia local, castração, ovariectomia, gata.

Abstract: We evaluates the safeness and efficacy of local anesthesia for ovariectomies in 15 female in cats. Surgery was performed by bilateral laparotomy in the flank in 15 female cats of different weight and age. Cats were tranquilized with 5 $\mathrm{mg} / \mathrm{kg}$ of $0.2 \%$ acepromazine and surgery site was infiltrated locally with $2 \%$ lidocaine at a maximum doses of $7 \mathrm{mg} / \mathrm{kg}$. Ovaries were found after location of the kidneys by external palpation. After the opening of the abdominal cavity, the ovaries were exteriorized, ligated by transfixation and removed. The abdominal wall and skin were sutured with interrupted simple suture. A week after the operation, the cutaneous suture were removed. The anesthetic technique employed was efficient and the surgical technique easy to perform. When the cutaneous sutures were removed, the cats were clinically normal and showed good recovery. It was concluded that the anesthetic technique can be successful used in cats for ovariectomies by flank.

Key words: Local anesthesia, spaying, ovariectomy, cat.

\section{Introdução}

A acepromazina é um tranqüilizante de baixa toxicidade (FIALHO,1985; THURMON et al., 1996) e com DL50 alta, variando de $61,37 \mathrm{mg} / \mathrm{kg}$ quando utilizada por via intravenosa (THURMON et al., 1996) a $70 \mathrm{mg} / \mathrm{kg}$ (MASSONE, 1988). Em felinos, esta droga é recomendada como medicação pré-anestésica (MASSONE, 1988), na dosagem de 0,025 a 0,2 mg/kg (BERNARDSKI, 1996). No entanto, não ocorrem efeitos colaterais com freqüência ao se empregar doses elevadas de acepromazina em pequenos animais (HALL; CLARKE, 1987).

Para se realizar ovariectomias em gatas, aconselhase o uso de anestesia geral (HICKMAN; WALKER, 1977; DIETZ et al., 1979; HEDLUND, 1997), mas quando não se usa anestésico geral nesta cirurgia, a sedação deve ser feita com doses elevadas de tranquilizantes (HEDLUND, 1997).

A esterilização cirúrgica é o método mais efetivo e de baixo risco para esterilizar a gata (WILDT et al., 1977).
Para isto, aconselha-se a ovariohisterectomia (WILDT et al., 1977; WILSON; HAYES, 1991; STONE et al., 1993) ou a ovariectomia (HICKMAN; WALKER, 1977; DIETZ et al., 1979; ALEXANDER, 1981; MIALOT, 1998).

Em relação a ovariectomia em gatas, ela pode ser realizada por via mediana (DIETZ et al., 1979; ALEXANDER, 1981), no entanto, a laparotomia pelo flanco é considerada a via de acesso mais satisfatória. (MIALOT, 1998). Esta cirurgia pode ser feita com uma pequena incisão na fossa paralombar esquerda, retirando-se os dois ovários pela mesma incisão, mas a manobra para expor o ovário direito é difícil (HICKMAN; WALKER, 1977).

L.A.A. Janssens e G.H.R.R. Janssens (1991) realizaram ovariectomia por laparotomia bilateral pelo flanco em 72 cadelas. Citaram como vantagens: melhor exposição ovariana, mais segurança na ligadura permitindo colocação profunda e incisões pequenas. Como desvantagens os autores enumeraram: necessidade de mudar a posição do animal, dificuldade em encontrar a bursa ovariana e dificuldade de remover o útero quando

\footnotetext{
2 Professor, doutor, Universidade Federal do Piauí e UNOPAR.

${ }^{3}$ Médica veterinária autônoma, Teresina, PI.

${ }^{4}$ Estudante de química, Universidade Federal do Piauí.
} 
necessário. As complicações pós-operatórias imediatas foram mínimas e constaram de seroma em $26 \%$ dos cães. Com acompanhamento de 10 anos, não ocorreu piometra.

Uma das principais causas de piometra é o excesso de progesterona. Como a gata só desenvolve o corpo lúteo (responsável pela produção de progesterona) após a cópula, a piometra nesta espécie é bem menos freqüente, quando comparada com a espécie canina (HEDLUND, 1997).

Foram realizadas ovariectomias em gatas através de laparotomia pelo flanco, com o objetivo de torná-las menos invasivas e fazendo-se uso de anestésico local para reduzir custos, o que permite a vantagem adicional de poder ser utilizada em larga escala, principalmente nos mutirões de castração, os quais vem sendo realizados em vários pontos do território nacional (GARCIA; CIAMPI, 1996, CLÍNICA VETERINÁRIA, 1997).

\section{Material e Métodos}

Foram utilizadas 15 gatas de diversas idades (mínimo de 3 meses), não gestantes, selecionadas entre a clientela da Clínica de pequenos animais da Universidade Federal do Piauí. Uma vez selecionados, os animais foram submetidos a exames clínicos para avaliação do risco cirúrgico. As gatas consideradas clinicamente sadias foram tranqüilizadas com acepromazina na dose de $5 \mathrm{mg} / \mathrm{kg}$ por via intramuscular. Foi canulada a veia cefálica e administrada solução de ringer lactato na dose aproximada de $5 \mathrm{ml} / \mathrm{kg} /$ hora com o objetivo de manter uma veia disponível. Após tricotomia e antisepsia (com álcool-iodado) bilateral da região da fossa paralombar, foi realizada palpação para localização dos rins que serviram como referência anatômica. Uma vez localizados os rins, foi feita infiltração de lidocaína a $2 \%$ na dose máxima de $7 \mathrm{mg} / \mathrm{kg}$ nas fossas paralombares (paralelamente às vértebras lombares e transversalmente às costelas), com técnica de L invertido (MASSONE, 1994). A infiltração abrangeu pele, subcutâneo, músculos e peritônio. Após o teste para se observar se a região estava anestesiada, foram executadas incisões bilaterais nas fossas paralombares, tendo sempre como referência os rins já que os ovários estão localizados caudalmente a estes. Todos os planos foram incisados: pele, subcutâneo, músculos e peritônio. Com a abertura da cavidade abdominal, os ovários foram localizados, pinçados e ligados por transfixação com fio de nylon 30 , a cavidade abdominal foi inspecionada e instilado antibiótico tópico. O peritônio foi suturado junto com os músculos da parede, utilizando-se pontos separados simples com categute cromado 3-0, e a pele com pontos separados simples, usando-se fios de nylon 3-0. Ao término da cirurgia, o animal foi entregue ao proprietário e foi feita a prescrição de flunixin meglumine na dose de $1,1 \mathrm{mg} / \mathrm{kg}$ sid durante três dias. Uma semana depois foram retirados os pontos e os animais foram avaliados clinicamente, observando-se parâmetros como edema, deiscência, infecções e quaisquer outras alterações.

\section{Resultados e Discussão}

A esterilização cirúrgica é o método mais efetivo e de baixo risco para esterilizar a gata (WILDT et al., 1977). O trabalho em questão apresenta uma alternativa eficiente, barata e segura de suprimir o cio em gatas por método cirúrgico, utilizando-se anestesia local, o que reduz consideravelmente os custos da cirurgia.

O tranqüilizante empregado neste trabalho foi a acepromazina pois a mesma tem indicação de uso em felinos (MASSONE, 1994; BERNARDSKI, 1996). A dosagem utilizada de acepromazina pode ser considerada alta, de acordo com a literatura (BERNARDSKI, 1996). No entanto, não ocorreram reações adversas detectáveis clinicamente que pudessem ser atribuídas à utilização de acepromazina na dosagem preconizada. Provavelmente isso se deve ao fato de que a acepromazina é uma droga que apresenta baixa toxicidade (FIALHO, 1985; THURMON et al., 1996) e DL-50 alta (MASSONE, 1994; THURMON et al., 1996). Além disso, não ocorrem efeitos colaterais com maior freqüência ao se empregar doses elevadas de acepromazina em pequenos animais (HALL; CLARKE, 1987). Contribuiu para o fato de se utilizar dosagem alta de acepromazina a afirmativa de que, quando se usa anestésico local para ovariectomias em gatas a sedação deve ser realizada com doses elevadas de tranquilizantes (HEDLUND, 1997).

Embora a literatura indique a anestesia geral para realização de ovariectomia em gatas (HICKAMN; WALKER, 1977; DIETZ et al., 1979; HEDLUND, 1997), a anestesia local utilizada neste trabalho mostrou-se eficiente, barata e segura.

Alguns autores indicam a ovariohisterectomia para supressão de cio em gatas (WILDT et al., 1977; WILSON; HAYES, 1991; STONE et al., 1993), mas outros preconizam apenas a ovariectomia (HICKMAN; WALKER, 1977; DIETZ et al., 1979; ALEXANDER, 1981; MIALOT, 1998). A indicação para a retirada de ovário e útero é devida ao risco de formação de piometra em útero inativo, sendo que uma das principais causas desta piometra é o excesso de progesterona. Como a gata só desenvolve o corpo lúteo (responsável pela produção de progesterona) após a cópula, a piometra nesta espécie é menos freqüente, quando comparada com a espécie canina (HEDLUND, 1997). Esta afirmação permite que a técnica seja empregada com risco mínimo de formação de piometra.

Apesar da indicação de laparotomia mediana para realização de ovariectomia em gatas (DIETZ et al.; 1979; ALEXANDER, 1981), neste trabalho optou-se por laparotomia pelo flanco por ser menos invasiva. A decisão foi acertada pois a técnica cirúrgica revelou-se de fácil execução e com mínima invasão tecidual. Outros autores dão embasamento à opção pela citada técnica, não só na gata (HICKAMN; WALKER, 1977; MIALOT, 1998) como na cadela (JANSSENS, L.A.A.; JANSSENS, G.H.R.R., 1991). A maior dificuldade foi a localização do ovário, 
dificuldade esta que foi superada após as três primeiras cirurgias. Optou-se pela laparotomia bilateral pela facilidade de exposição dos ovários.(HICKMAN; WALKER, 1977).

Neste trabalho todos os animais mostraram boa recuperação no pós-operatório imediato não se observando reações patológicas dignas de nota. O mesmo ocorreu em estudo semelhante com cadelas (JANSSENS, L.A.A.; JANSSENS, G.H.R.R., 1991).

Por ocasião da retirada dos pontos todos os animais apresentavam cicatrização normal e sem alterações.

\section{Conclusões}

Diante das condições deste experimento, concluiuse que:

1) a ovariectomia em gatas pode ser realizada sob anestesia local infiltrativa;

2) a ovariectomia em gatas pode ser realizada por laparotomia bilateral pelo flanco.

\section{Referências}

ALEXANDER, A.. Ovariectomia en felinos y caninos; laparotomia umbilical. In: _. Técnica quirurgica em animales y temas de terapêutica quirurgica. México: Interamericana, 1981. p. 192-6.

BERNARDSKI, R.M. Anesthesia and immobilization of specific species; dogs and cats. In: THURMON,J.C.; TRANQUILLI,W.J.; BENSON,G.J. Veterinary anesthesia. 3. ed. Baltimore: Williams \& Wilkins, 1996. p. 591-8.

CIDADE de São Paulo aprova lei para controle da população de Cães e gatos. Clínica veterinária, v.2, n. 10, p.44, 1997.

DIETZ, O.; SCHAETZ, F.; SCHLEITER, H. Operacio-nes en los ovarios. In: TEUSCHRER, R. Operaciones y anesthesia de los grandes y pequenos animales. 2. ed. Zaragoza: Acribia, 1979. p. 492-500.

FIALHO, S.A.G. Medicação pré-anestésica. In: Anestesiologia veterinária. São Paulo: Nobel, $1985 . \mathrm{p}$. 40-52.
GARCIA, R.M.; CIAMPI, M. Campanha de controle das populações de cães e gatos no município de Taboão da Serra, São Paulo, Brasil. [S. I.]: Noé Consultoria em Bem Estar Animal, 1996. 27p. (Apostila).

HALL, L.W.; CLARKE, K.W. Anestesia do cão. In: Anestesia veterinária. 8. ed. São Paulo: Manole, 1987. p. 331-69.

HEDLUND, C. S. Surgery of the reproductive and genital systems. In: FOSSUM, T. W. Small animal surgery. Saint Louis: Mosby, 1997. p.517-74.

HICKMAN, J.; WALKER, R.G. Ovariectomia en la gata. In: . Atlas de Cirugia Veterinaria. México: Continental, 1977. p.96-7.

JANSSENS, L.A.A.; JANSSENS, G.H.R.R. Bilateral Flank ovariectomy in the dog - surgical technique and sequelae in 72 animals. Journal of Small Animal Practice, v. 32, n.5, p.249-52, 1991.

MASSONE,F. Anestesiologia Veterinária. 2. ed. Rio de Janeiro: Guanabara Koogan, 1994.

MIALOT, J.P. Cirurgia do aparelho genital feminino. In: Patologia da reprodução dos carnívoros domésticos. Porto Alegre: Hora Veterinária, 1998. p.1429.

STONE, E.A; CANTRELL, C.G.; SHARP, N.J.H. Ovary and uterus. In: SLATTER, D. Textbook of small animal surgery. 2. ed. Philadelphia: W.B. Saunders, 1993. v.2, p.1293308.

THURMON, J.C.; TRANQUILLI, W.J.; BENSON, G.J. Preanesthetics and anesthetic adjuncts. In:

Veterinary anesthesia. 3.ed. Baltimore: Williams \& Wilkins, 1996. p. 591-8.

WILDT,D.E.; KINNEY,G.M.; SEAGER,S.W.J. Reproduction comtrol in the dog and cat: an examination and evaluation of current and proposed methods. Journal of animal hospital association, v.13, p.223, 1977 Apud WILDT,D.E. Estrous cycle control-induction and prevention in cats. In: MORROW, D.A. Current therapy in theriogenology. Philadelphia: W.B. Saunders, 1986. p.808-12.

WILSON, G.P.; HAYES Jr., H.M. Ovariohisterectomia em cadelas e gatas. In: BOJRAB,J.M.; CRANE, S.W.; ARNOCZKI, S.P. Cirurgia dos pequenos animais. 2. ed. São Paulo: Roca, 1991. p.365-9. 
